\title{
ESTUDO CINÉTICO E CARACTERIZAÇÃO DA FERMENTAÇÃO ALCOÓLICA DE UVAS DOS CULTIVARES NIAGÁRA
}

\author{
J. R. MELO ${ }^{1 *}$, M. R. BUENO ${ }^{1}$, A. D. D. CAVALCANTI ${ }^{1}$, R. G. MARQUES ${ }^{2}$ \\ ${ }^{1}$ Universidade Estadual de Maringá, *bolsista CAPES, Departamento de Engenharia Química \\ ${ }^{2}$ Faculdade de Telêmaco Borba, Departamento de Engenharia Química \\ E-mail para contato: rmjoelma@gmail.com
}

\begin{abstract}
RESUMO - Este trabalho apresenta um estudo teórico e experimental da cinética e fermentação alcoólica de uvas dos cultivares Niágara Rosada, utilizando a levedura Saccharomyces cerevisiae num fermentador de $2 \mathrm{~L} \mathrm{em}$ batelada. $\mathrm{O}$ mosto foi preparado em dois tratamentos: com correção de açúcar (chaptalização) e sem correção de açúcar. São apresentados os perfis de concentração de células, substratos e produto, como também os parâmetros fermentativos de rendimento, produtividade e eficiência na fermentação. O fermentado obtido possui algumas características físico-químicas e qualidades comparáveis a outros fermentados encontrados na literatura. Porém, com graduação alcoólica abaixo da exigida pela legislação brasileira, o que não foi possível classificá-lo como vinho de mesa. O processo fermentativo mais eficiente na produção do fermentado foi obtido com a correção do mosto, no qual o rendimento e a eficiência foram de $0,335 \mathrm{~g}_{\text {etanol }} / \mathrm{g}_{\text {glicose }}$ e $65,5 \%$, respectivamente.
\end{abstract}

\section{INTRODUÇÃO}

A fermentação do suco de uva em vinho é um processo bioquímico complexo, no qual as leveduras utilizam açúcares e outros constituintes do suco da uva, tal como o substrato para o seu crescimento, convertendo-os em etanol, dióxido de carbono e outros produtos finais do metabolismo, que contribuem para a composição química e qualidade do vinho (SENER et al., 2007).

$\mathrm{Na}$ vinificação tradicional, a fermentação era realizada por leveduras indígenas (leveduras existentes na uva e no suco da uva a ser fermentado); no entanto, isso está mudando, pois atualmente a fermentação pode ser induzida por leveduras selecionadas. Segundo Hashizume (2001) as leveduras são os micro-organismos agentes da fermentação alcoólica. De acordo com Zinnai et al. (2013), várias espécies de Saccharomyces têm sido amplamente utilizados na produção de vinhos. A espécie Saccharomyces cerevisiae é a levedura mais comum na fermentação alcoólica e, é utilizada pela capacidade de produzir e tolerar altas concentrações de etanol em meio ácido e com elevado conteúdo de açúcares. Além disso, são as mais adaptadas às condições industriais e de maior importância econômica envolvendo os processos biotecnológicos (LIMA et al., 2001). O conceito de inocular o suco da uva com fermentos selecionados de $S$. cerevisiae para incentivar a rápida fermentação tornouse amplamente aceito na indústria do vinho (SENER et al., 2007).

Os açúcares provenientes da uva são constituídos quase que exclusivamente de glicose e 


\section{9 a 22 de outubro de 2014 \\ Florianópolis/SC}

frutose, sendo responsáveis por 99\% dos carboidratos fornecidos à levedura, considerados como substrato para a fermentação (DAUDT e SIMON, 2001; LIMA et al., 2001). Entretanto, durante o processo de fermentação alcoólica com a espécie de levedura usualmente empregada, Saccharomyces cerevisiae, a glicose pode ser mais rapidamente fermentada do que a frutose, devido à preferência das enzimas que ativam a fermentação (HASHIZUME, 2001; LIMA et al., 2001). As reações enzimáticas dependem de diversos fatores: físicos, químicos e biológicos que estimulam ou reprimem a ação das enzimas, tais como a concentração de açúcar, pH e temperatura, que afetam o desenvolvimento da fermentação por meio das leveduras (LIMA et al., 2001; VAZ et al., 2008; ZINNAI et al., 2013).

O estudo cinético de um processo fermentativo analisa a evolução dos valores da concentração dos componentes do meio de cultivo (mosto), que são: o microrganismo (levedura - X), os produtos do metabolismo (álcoois - P) e os substratos (açúcares - S); em função do tempo em que ocorre a fermentação. Para o estudo cinético escolhe-se o produto de interesse econômico (álcool etílico) e o substrato limitante (glicose) (HISS, 2001).

No presente trabalho realizou-se um estudo da cinética fermentativa (perfis de concentração de leveduras, substrato e produto), dos parâmetros fermentativos (rendimento, produtividade e eficiência do processo) e caracterização físico-química do vinho produzido, verificando a influência da correção do mosto com adição de açúcar (chaptalização).

\section{METODOLOGIA}

A fermentação foi conduzida em batelada e o meio de cultivo na ausência de casca foi separado em dois recipientes com capacidade de $2 \mathrm{~L}$, sendo $950 \mathrm{~mL}$ de suco in natura em cada recipiente. Antes do início de cada ensaio, promoveu-se a correção na concentração de açúcar em um dos recipientes.

No processo de correção do mosto adotou-se o procedimento de chaptalização com sacarose, por meio da adição de $50 \mathrm{~g}$ de açúcar por litro de mosto, conforme metodologia de Góes e Zangirolami (2005), respeitando as restrições limites para não adulteração do vinho. Rizzon e Manfroi (2006) recomendam a adição de açúcar refinado previamente diluído em uma pequena quantidade do mosto. Utilizou-se Saccharomyces cerevisiae (fermento comum de panificação) como agente fermentador, obtido na forma seca junto ao mercado local, na quantidade de $0,4 \mathrm{~g} / \mathrm{L}$ do mosto. $\mathrm{O}$ inóculo foi preparado segundo metodologia de Góes e Zangirolami (2005), antes da sulfitagem do mosto, transferindo-se a levedura para $50 \mathrm{~mL}$ do mosto da uva sem casca e previamente fervido, mantido sob inoculação durante 24 horas à temperatura de $24^{\circ} \mathrm{C}$ e pH ácido, até pleno crescimento na superfície. O metabissulfito de sódio a $10 \%(\mathrm{~m} / \mathrm{v})$ segundo Corraza et al. (2001), foi utilizado na sulfitagem do mosto para eliminar micro-organismos indesejáveis (HASHIZUME, 2001).

O início da fermentação alcoólica ocorreu após transferência do inóculo para o meio de cultivo. Após, os recipientes foram vedados impedindo a entrada de ar e o mosto foi deixado em repouso à temperatura ambiente $\left(\sim 20^{\circ} \mathrm{C}\right)$, sob um período de $85 \mathrm{~h}$ de fermentação. 


\subsection{Estudo cinético}

Durante o processo de fermentação alcoólica foram obtidos dados referentes à concentração de substrato (açúcares), micro-organismos (levedura) e produto (etanol), analisando-se as amostras retiradas periodicamente em um intervalo de tempo, ao longo de $85 \mathrm{~h}$ do processo. As amostras foram inicialmente centrifugadas durante 5 minutos e os sobrenadantes foram utilizados para determinação da concentração de micro-organismos. A determinação da concentração de biomassa foi realizada por gravimetria.

\subsection{Parâmetros fermentativos}

Os parâmetros característicos do processo são: o fator de conversão de substrato em produto, produtividade e a eficiência do processo; calculados conforme equações descritas a seguir.

Fator de conversão de substrato em produto (Y $\left.\mathrm{Y}_{\mathrm{P} / \mathrm{S}}\right)(\mathrm{HISS}, 2001)$ :

$$
Y_{P / S}=\frac{\left(P_{m}-P_{0}\right)}{\left(S_{0}-S_{m}\right)}
$$

em que, $\mathrm{Y}_{\mathrm{P} / \mathrm{S}}$ é o rendimento da fermentação expresso pela quantidade de etanol formado por unidade de açúcar consumido; $\mathrm{P}_{\mathrm{m}}$ é a massa final de etanol, $\mathrm{P}_{0}$ é a massa de etanol inicial; $\mathrm{S}_{0}$ é a massa de substrato inicial, $\mathrm{S}_{\mathrm{m}}$ é a massa de substrato final.

Eficiência do processo fermentativo (PAVLAK et al., 2011):

$$
E=\frac{Y_{P / S}}{0,511} \cdot 100
$$

em que, E é a eficiência do processo em \%.

A produtividade da fermentação (HISS, 2001):

$$
P_{P}=\frac{\left(P_{m}-P_{0}\right)}{t_{f}}
$$

em que, $\mathrm{P}_{\mathrm{P}}$ é a produtividade do produto; e $\mathrm{t}_{\mathrm{f}}$ é o tempo total de fermentação.

\subsection{Caracterização físico-química}

As fermentações foram acompanhadas determinando-se a temperatura do mosto e observando o desprendimento de dióxido de carbono, além de determinações físico-químicas segundo normas analíticas descritas a seguir. Ao final, o fermentado obtido foi caracterizado e comparado a vinhos produzidos por outros pesquisadores. 


\section{9 a 22 de outubro de 2014 \\ Florianópolis/SC}

\subsection{1 pH e temperatura}

$\mathrm{O} \mathrm{pH}$ foi determinado através de um pHmetro digital, conforme normas analíticas do Instituto Adolf Lutz (IAL, 2008). Mediu-se o valor do $\mathrm{pH}$ diretamente na amostra contida em béqueres de 100 $\mathrm{mL}$, mergulhando o eletrodo na amostra analisar. Efetuaram-se pelo menos três determinações em cada amostra, tomando como resultado a média aritmética das leituras realizadas. Determinou-se a temperatura do mosto em fermentação com um termômetro convencional de mercúrio em escala de graus Celsius inserido dentro do fermentador.

\subsubsection{Sólidos solúveis totais $\left({ }^{\circ}\right.$ Brix) e concentração de sacarose}

O teor de sólidos solúveis foi aferido por leitura direta em refratômetro portátil para açúcar. $\mathrm{Na}$ determinação da concentração de sacarose, a propriedade utilizada foi $\mathrm{o}{ }^{\circ}$ Brix, segundo uma correlação linear entre o grau Brix e a concentração de açúcar (TORRES NETO et al., 2006), dada pela equação 4.

$$
C A=10,13 \cdot\left({ }^{\circ} \text { Brix }\right)+1,445
$$

em que, CA é a concentração de açúcar em gramas por litro.

\subsubsection{Teor alcoólico}

O grau alcoólico foi determinado por densimetria, utilizando-se um alcoômetro de Gay-Lussac. Considerando-se a densidade do etanol $(\rho)$, pode-se estimar, a partir do teor alcoólico, a quantidade de álcool por litro de vinho (g/L) produzido durante a fermentação (CARVALHO et al., 2008).

\section{RESULTADOS E DISCUSSÕES}

O processo foi realizado em condições variáveis ( $\mathrm{T}, \mathrm{pH}$, etc.), a fim de se observar, quantificar e comparar a influência da correção no mosto. Para fins comparativos não houve reposição de açúcar durante o processo de fermentação.

\subsection{Fermentação alcóolica}

A Figura 1 apresenta os perfis de consumo de substrato (S), crescimento de micro-organismo (X) e produção de etanol (P), em função do tempo de fermentação.

Verifica-se que durante o processo de fermentação houve um crescimento de células (X), durante as $72 \mathrm{~h}$ de fermentação e, após este período, pôde-se visualizar uma estabilização do crescimento. Observou-se que a curva de crescimento para o mosto corrigido teve desde o início da fermentação um maior crescimento de leveduras do que para o mosto sem correção; isto pode ser explicado devido à suplementação de açúcar no mosto, onde os micro-organismos teriam uma maior quantidade de substrato como fonte para sua multiplicação e crescimento. A utilização de $0,4 \mathrm{~g} / \mathrm{L}$ de levedura (Saccharomyces cerevisiae), mostrou-se inadequada para obtenção de teores alcoólicos 
dentro dos padrões exigidos para fermentação alcoólica.
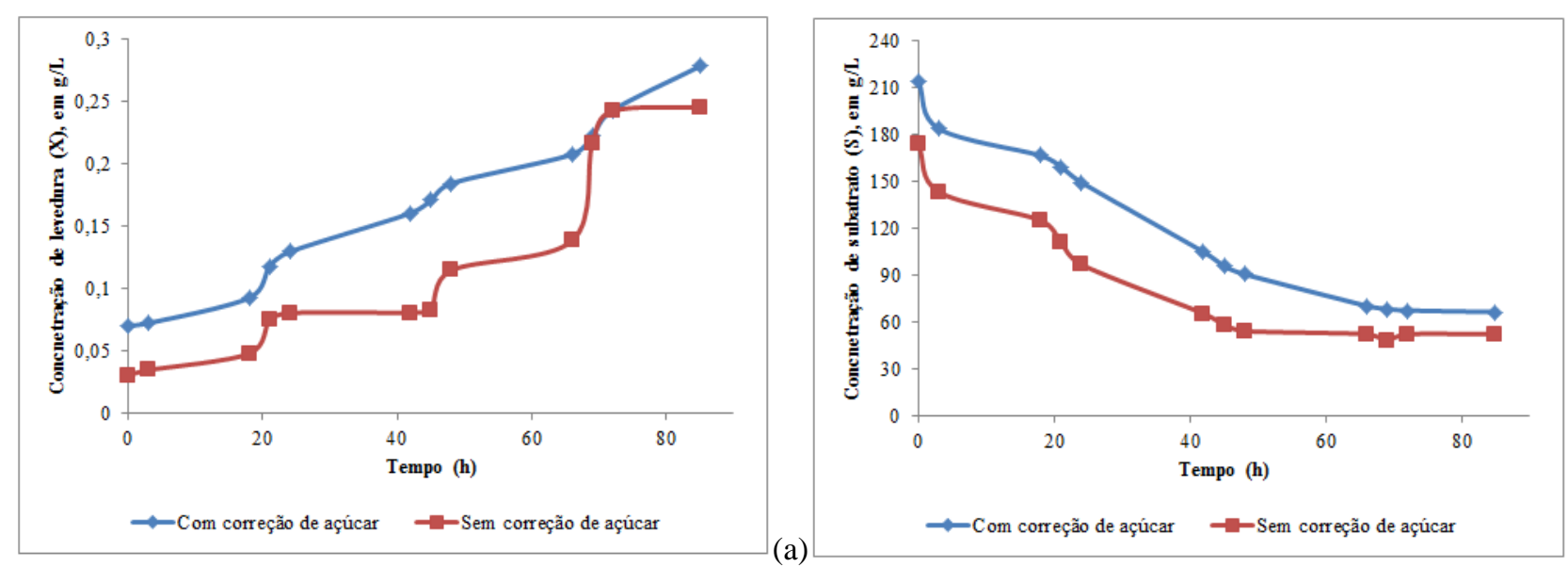

(a)

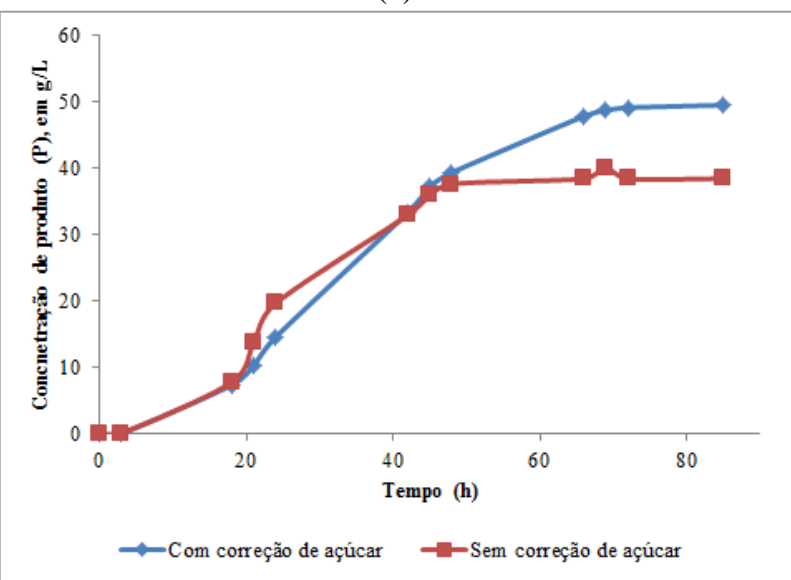

(c)

Figura 1 - Cinética da fermentação alcoólica da produção de vinho. Análise do comportamento: (a) da concentração de levedura (X), (b) concentração de substrato (S) e concentração de etanol (P), nos dois experimentos, com correção e sem correção do mosto.

O consumo de substrato pela ação dos micro-organismos resultou em um decaimento na concentração de açúcar (S), até 48h de fermentação. Após 66h de fermentação, ocorreu uma estabilização, verificando-se um decaimento mais lento, devido ao aumento da concentração de etanol presente no mosto em fermentação. Em ambos os experimentos houve um decréscimo proporcional, a nível de concentração de açúcar.

A concentração de álcool durante a fermentação alcoólica foi proporcional em ambos os casos estudados, exceto para o valor final da graduação alcoólica. Até 45h de fermentação a produção de álcool seguiu praticamente a mesmo comportamento para os dois experimentos. A partir de $48 \mathrm{~h}$ de fermentação o mosto corrigido continuou a produzir álcool até obter uma graduação alcoólica de $6,3^{\circ} \mathrm{GL}$, resultando em um fermentado com 49,8 gramas de álcool por litro de vinho. No entanto, para o mosto sem correção a graduação alcoólica obtida foi de $4,9^{\circ} \mathrm{GL}$ e um fermentado com 38,7 gramas de álcool por litro de vinho. Observou-se, após $69 \mathrm{~h}$ de fermentação, uma diminuição na velocidade de 


\section{9 a 22 de outubro de 2014 \\ Florianópolis/SC}

produção no mosto sem correção e, após $72 \mathrm{~h}$, uma estabilização da produção para o mosto com correção de açúcar; reflexo da inibição celular pelo produto. A adição de açúcar, como era esperado, foi significativa para a produção de etanol; isto porque, maiores teores de sólidos solúveis totais (SST) favorecem uma maior produção de etanol.

Com base no monitoramento cinético, a produção de etanol foi observada durante $85 \mathrm{~h}$ de fermentação. A partir dos resultados pode-se verificar o rendimento, a eficiência e a produtividade da fermentação conforme Tabela 1.

Tabela 1 - Parâmetros fermentativos nos dois tratamentos

\begin{tabular}{cccc}
\hline Tratamento & $\begin{array}{c}\text { Rendimento } \\
\left(\mathrm{g}_{\text {etanol }} / \mathrm{g}_{\text {glicose }}\right)\end{array}$ & Eficiência (\%) & Produtividade (g/L.h) \\
\hline $\mathrm{A}^{*}$ & 0,335 & 65,497 & 0,582 \\
$\mathrm{~B} * *$ & 0,316 & 61,819 & 0,452 \\
\hline
\end{tabular}

*Com correção de açúcar, ** sem correção de açúcar.

$\mathrm{O}$ fator de rendimento $\left(\mathrm{Y}_{\mathrm{P} / \mathrm{S}}\right)$ para ambos os tratamentos foi de valores muito próximos, que variam de $0,335 \mathrm{~g}_{\text {etanol }} / \mathrm{g}_{\text {glicose }}$ e $0,3316 \mathrm{~g}_{\text {etanol }} / \mathrm{g}_{\text {glicose }}$ para o mosto com e sem correção, respectivamente; e eficiências que correspondem à conversão de aproximadamente 65,5\% a 62\% dos açúcares totais presentes no meio. Para efeito comparativo, obteve-se na literatura que o rendimento de etanol, em relação ao substrato consumido, na prática, situa-se entre os valores de 0,465 e $0,485 \mathrm{~g}_{\text {etanol }} / \mathrm{g}_{\text {glicose }}$ (GÓES e ZANGIROLAMI, 2005). O mesmo pôde ser verificado para a produtividade, que variou entre os diferentes tratamentos, demostrando que a correção do mosto, pela adição de açúcar, melhorou o desempenho do processo fermentativo.

$\mathrm{O}$ baixo valor obtido para $\mathrm{Y}_{\mathrm{P} / \mathrm{S}}$ pode ser atribuído à levedura utilizada no experimento, que provavelmente não possui o melhor rendimento em etanol, necessário para a produção do vinho a partir das uvas alternativas utilizadas neste trabalho. Sabe-se que as uvas americanas não possuem o mesmo potencial vínico que as uvas viníferas (BARNABÉ, 2007).

\subsection{Caracterização físico-química}

O fermentado avaliado neste trabalho é do tipo doce, cujo teor de açúcar esteve entre 66,3 e $52,1 \mathrm{~g} / \mathrm{L}$, classificado nesta categoria segundo a legislação brasileira (UNIVIBRA, 2009), e de cor branca, apesar da uva ser rosada. Esta é uma das características desde cultivar, segundo Barnabé et al. (2007). Inicialmente notou-se o vinho rosado, porém o mesmo perdeu rapidamente suas características de cor, comprovando que a cor do vinho não depende necessariamente do tipo de uva, mas também do processo de vinificação utilizado (HASHIZUME, 2001). A fermentação foi realizada na ausência de casca, obtendo-se assim, um fermentado incolor. A Tabela 2 apresenta uma comparação entre o vinho produzido e os vinhos de uva produzidos por outros pesquisadores.

Comparando-se os fermentados, verifica-se que o $\mathrm{pH}$ dos vinhos são relativamente próximos, exceto para o vinho de Corazza et al. (2001). Quanto ao grau ${ }^{\circ}$ Brix, o vinho obtido com correção do mosto teve um valor bem próximo do valor apresentado por Corazza et al. (2001), enquanto que os 
vinhos de Torres Neto et al. (2006), apresentam uma menor concentração final, justificando os maiores teores de álcool em comparação com os demais vinhos.

Tabela 2 - Comparação com outros vinhos da literatura

\begin{tabular}{c|cccc}
\hline & $p H$ & Grau Brix & Grau alcoólico & Odor assimilado \\
\hline Vinho A $^{\mathrm{a}}$ & 3,56 & 6,4 & 6,3 & de uva \\
Vinho B $^{\mathrm{b}}$ & 3,5 & 5,0 & 4,9 & \\
Vinho branco (uva)* $^{*}$ & 3,3 & $2,0^{1}$ & 12,2 & de uva \\
Vinho tinto (uva)* $^{*}$ & 3,6 & $3,4^{1}$ & 12,0 & de uva \\
Vinho tinto (uva)** $^{*}$ & 2,9 & 6,5 & 10,3 & de uva \\
\hline
\end{tabular}

${ }^{a}$ Vinho deste trabalho (uva Niágara Rosada) com correção de açúcar, ${ }^{b}$ vinho deste trabalho (uva Niágara Rosada) sem correção de açúcar, *Torres Neto et al. (2006), **Corazza et al. (2001). ${ }^{\text {V Valores }}$ de concentração de açúcar em $(\mathrm{g} / \mathrm{L})$.

A concentração de açúcar e levedura do mosto em fermentação não foi suficiente para a produção de um vinho com uma graduação alcoólica exigida pela legislação brasileira para que fosse classificado como vinho de mesa $\left(8,6\right.$ a $\left.14^{\circ} \mathrm{GL}\right)$. Acredita-se que um mosto suplementado com nutrientes extras, a concentração e o tipo de substrato, assim como uma variedade selecionada de levedura ou um inóculo com uma carga de fermento melhor adaptada ao mosto, contribuiriam para se obter um comportamento de fermentação mais próximo do esperado, ou seja, quando o consumo de açúcares acusa atenuação completa $\left(0^{\circ}\right.$ Brix $)$, o que não foi observado no presenta trabalho.

\section{CONCLUSÕES}

Com base nos resultados verifica-se que a adição de açúcar foi significativa para que o fermentado alcançasse uma maior produção de etanol. Este comportamento é devido à formação do produto (etanol) estar associada ao crescimento e diretamente ligada às reações de redução e oxidação (catabolismo) do substrato (açúcares). Verificou-se assim, que o mosto tratado obteve maior teor alcoólico, rendimento e produtividade, sendo, portanto, considerado o processo fermentativo mais eficiente na produção do fermentado. A caracterização físico-química mostrou que o fermentado apresenta algumas qualidades comparáveis a vinhos encontrados na literatura. No entanto, constatouse uma graduação alcoólica abaixo da exigida pela legislação brasileira, o que não foi possível classificá-lo como vinho de mesa.

\section{REFERÊNCIAS}

BARNABÉ, D.; FILHO, W. G. V.; BOLINI, H. M. A. Análise descritiva quantitativa de vinhos produzidos com uvas Niágara rosada e bordô. Braz. J. Food Technol., v. 10, n. 2, p. 122-129, 2007.

CARVAlHO, W.; CANILHA, L.; ALMEIDA E SILVA, J. B. Cinética Fermentativa e balanço de massa da produção da produção de cachaça artesanal. Braz. J. Food Technol, v. 11, p. 2-08, 2008.

CORAZZA, M. L.; RODRIGUES, D. G.; NOZAKI, J. Preparação e caracterização do vinho de laranja. Química Nova, v. 24, n. 4, p. 449-452, 2001.

DAUT, C. E.; SIMON, J. A. Um método rápido para análise de glicose em mostos e sua quantificação 


\section{9 a 22 de outubro de 2014 \\ Florianópolis/SC}

em algumas cultivares do Rio Grande do Sul. Ciênc. Rural, v. 31, n. 4, p. 697-701, 2001.

GÓES, F. J.; ZANGIROLAMI, T. C. Optimization of the fermentation conditions for wine produced from the "Italia" grape variety. In $2^{\text {nd }}$ Mercosur Congress on Chemical Engineering, $4^{\text {th }}$ Mercosur Congress on Process Systems Engineering, Costa Verde, Rio de Janeiro. Disponível em: <http://www.enpromer2005.eq.ufrj.br/nukleo/pdfs/0825_artigo_enpromer_corrigido_goes.pdf >. Acesso em: 22 fev. 2014.

HASHIZUME, T. Tecnologia do vinho. Em: AQUARONE, E.; BORZANI, W.; SCHMIDELL, W.; LIMA, U. A. Biotecnologia na Produção de Alimentos. São Paulo: Edgard Blücher, 2001.

HISS, H. Cinética de processos fermentativos. Em: SCHMIDELL, W.; LIMA, U. A.; AQUARONE, E.; BORZANI, W. Engenharia Bioquímica. São Paulo: Edgard Blücher, 2001.

INSTITUTO ADOLF LUTZ. Métodos físico-químicos de alimentos. São Paulo: Instituto Adolf Lutz, $2008 . \quad$ Disponível em: <http://www.ial.sp.gov.br/index.php?option=com_remository\&Itemid=0\&func=select\&orderby=1>. Acesso em: 03 de mar. 2014.

LIMA, U. A.; BASSO, L. C.; AMORIM, H. V. Produção de etanol. Em: LIMA, U. A.; AQUARONE, E.; BORZANI, W.; SCMIDELL, W. Processos fermentativos e enzimáticos. São Paulo: Edgard Blücher, 2001.

PAVLAK. M. C. M.; ABREU-LIMA, T. L.; CARREIRO, S. C.; PAULILLO, S. C. L. Estudo da fermentação do hidrolisado de batata-doce utilizando diferentes linhagens de Saccharomyces cerevisiae. Química Nova, v. 34, n. 1, p. 82-86, 2011.

RIZZON, L. A.; MANFROI, L. Sistema de produção de vinho tinto. Embrapa uva e vinho: dezembro, $2006 . \quad$ Disponível em: $<$ http://sistemasdeproducao.cnptia.embrapa.br/FontesHTML/Vinho/SistemaProducaoVinhoTinto/fer mentacao.htm>. Acesso em: 27 mar. 2014.

SENER, A.; CANBAS, A.; UNAL, M. U. The effect of fermentation temperature on the growth kinetics of wine yeast species. Turk. J. Agric. For., v. 31, p. 349-354, 2007.

TORRES NETO, A. B.; SILVA, M. E.; SILVA, W. B.; SWARNAKAR, R.; SILVA, F. L. H. Cinética e caracterização físico-química do fermentado do pseudofruto do caju (Anacardium occidentale L.). Química Nova, v. 29, n. 3, p. 489-492.

UNIÃO BARSILEIRA DE VITIVINICULTURA. Portaria $n^{\circ}$ 229, de 25 de Outubro de 1988. 2009. Disponível em: 〈http://www.uvibra.com.br/legislacao_portaria229.htm〉. Acesso em: 26 mar. 2014.

VAZ, R. S.; PRADO, M. R. M.; CARVALHO, F. Biotecnologia na Indústria farmacêutica. Revista Biotecnologia Ciência \& Desenvolvimento, n. 73, p. 36-39, 2008.

ZINNAI, A.; VENTURI, F.; SANMARTIN, C.; ANDRICH, G. The kinects of alcoholic fermentation by two yeast strains in high sugar concentration media. J. Bioproces. Biotech., v. 3, n. 2, p. 1-5, 2013. 